\title{
Does Hypothyroidism Affect Post-Operative Outcome of Patients Undergoing Carpal Tunnel Release?
}

\author{
Sharareh Roshanzamir ${ }^{1}$, Sahameddin Mortazavi ${ }^{2}$, Alireza Dabbaghmanesh ${ }^{3}$
}

\author{
${ }^{1}$ M.D., Physiatrist, Assistant Professor, Shiraz Burn Research Center, Shiraz University of Medical Sciences, \\ Shiraz, Iran \\ ${ }^{2}$ M.D., Student Research Committee, International Branch, Shiraz University of Medical Sciences, Shiraz, Iran \\ ${ }^{3}$ M.D, Internist, Assistant Professor, Shiraz Endocrine and Metabolism Research Center, Shiraz University of \\ Medical Sciences, Shiraz, Iran
}

\section{Type of article: Original}

\begin{abstract}
Introduction: Risk factors associated with Carpal Tunnel Syndrome include repetitive use of hand and wrist, advanced age, obesity, pregnancy, diabetes mellitus and thyroid disease. Decompression of the median nerve is the last treatment of choice usually indicated when negative results to conservative treatments remain for three months. In this study, we aimed to find out whether hypothyroid patients would respond to CTS surgical decompression differently in comparison to healthy individuals.

Methods: This case control study was conducted on patients with CTS in need of surgical release who were refered to Shahid Faghihi hospital, International Branch of Shiraz University of Medical Sciences, Shiraz, Iran from January 2013 to January 2015. Twenty-five hypothyroid and 22 euthyroid patients were recruited. Hypothyroidism was diagnosed based on clinical symptoms and serum TSH level. All patients were followed for three weeks after surgery and a Boston Carpal Tunnel Syndrome Questionnaire (BCTQ) was completed for them pre and post operation. An electrophysiological study was performed during the same follow up period. Statistical analysis was performed using SPSS version 16.

Results: The CTS grade reported by electrophysiological study, decreased significantly 3 weeks after operation in comparison with preoperative grades $(\mathrm{p}<0.001)$. A significant decrease was observed in the immediate postoperative BCTQ scores compared to preoperative $(p<0.001)$. Also a decrease was detected in the three weeks of postoperative follow up compared to immediate postoperative BCTQ scores $(p<0.001)$ and preoperative BCTQ scores $(\mathrm{p}<0.001)$. Postoperative BCTQ scores of euthyroid patients decreased more in comparison to hypothyroid patients $(\mathrm{p}<0.001)$.
\end{abstract}

Conclusion: It seems that, hypothyroidism has an effect on postoperative outcome of carpal tunnel release.

Keywords: Carpal tunnel syndrome, Hypothyroidism, Boston carpal tunnel syndrome questionnaire

\section{Introduction}

\subsection{Background and Statement of the problem}

Focal neurophaty of the median nerve at the wrist, known as the carpal tunnel syndrome (CTS), is one of the most common peripheral entrapment neuropathies with prevalence of $3.7 \%$ to $5.8 \%$ in the general population (1). As CTS affects daily activities and quality of life in many patients, it is considered as a significant health problem. Different fields of internal medicine or surgery would frequently encounter CTS both as care givers or patients (2). Traditionally known risk factors for CTS include repetitive use of hand and wrist, advanced age, obesity, pregnancy, acromegaly, amyloidosis, diabetes mellitus, renal diseases, trauma, osteoarthritis and thyroid diseases (3). The most important pathologic characteristics of CTS is the increase in the carpal tunnel pressure disrupting the blood flow in the median nerve causing damage (4). Patients with CTS usually complain of pain, paraesthesia and weakness in the hand, especially in the first three fingers worsening at nights (5). The exact pathogenesis of peripheral nerve

\section{Corresponding author:}

Dr. Sahameddin Mortazavi, Student Research Committee, International Branch, Shiraz University of Medical Sciences, Shiraz, Iran. Tel: +98.9129470032, Fax: +98.7132319040, Email: sahammortazavi@yahoo.com

Received: April 09, 2016, Accepted: June 22, 2016, Published: September 2016

iThenticate screening: June 20, 2016, English editing: July 24, 2016, Quality control: August 22, 2016

(C) 2016 The Authors. This is an open access article under the terms of the Creative Commons Attribution-NonCommercialNoDerivs License, which permits use and distribution in any medium, provided the original work is properly cited, the use is non-commercial and no modifications or adaptations are made. 
abnormalities in patients with thyroid disease is still unknown. It proposed that mono and poly neuropathies are caused by different mechanisms. It has been assumed that mucinous deposits in the soft tissues around the peripheral nerves compress the nerve leading to mononeuropathy and polyneuropathy, caused by a demyelinating process or primary axonal degeneration (6). It has also been reported that the nerve conduction studies of $29 \%$ of hypothyroid patients might be positive for CTS (7). Decompression of the median nerve is the last treatment of choice which is usually considered in CTS patients with negative answer to conservative treatments. In this regard, CTS surgery can generally be successful (8) but surgeon's skill, pre and post-operative care and underlying disease can alter the outcome.

\subsection{Objective}

In present study, we aimed to find out whether hypothyroid patients would respond to CTS surgical decompression differently in comparison to the healthy individuals by means of the Boston CTS Questionnaire (BCTQ) and electrophysiological study.

\section{Material and Methods}

\subsection{Study Design}

This study was held as a case control study on patients with CTS in need of surgical release, who were referred to Shahid Faghihi hospital, International Branch of Shiraz University of Medical Sciences, Shiraz, Iran from January 2013 to January 2015.

\subsection{Study Population}

Patients were consecutively recruited and assigned to two groups. The first group were patients with hypothyroidism, which was diagnosed based on clinical symptoms and serum TSH level and the second group were euthyroid. CTS was diagnosed as if positive clinical signs and symptoms were present. Also electrophysiological findings should be suggestive for a CTS patient to be enrolled into the study. Indications for a surgical release of the median nerve included failed conservative treatment of more than 3 months or severe CTS diagnosed by electrophysiological study. Patients with the following characteristics were excluded: history of pregnancy, trauma to wrist or hand, previous carpal tunnel release; associated disease that was considered to have effect on the outcome such as diabetes mellitus, rheumatoid arthritis, cervical radiculopathy, other tenosynovitis of the same hand, such as trigger finger or de Quervain disease.

\subsection{Clinical evaluation}

All patients were observed for 3 weeks after surgery and a BCTQ was completed for them before the surgery, the day after surgery and three weeks after surgery. The following data were obtained for each patient before the operation, the post-operative day, and one week after the operation: Patients' physical examination, and the BCTQ scores, were used in the follow-up of CTS patients. The BCTQ was defined by Levine et al. (8) in 1993 and since then it has been a reliable scoring system for the clinical follow-up of CTS patients which has been translated into various languages (9). In this questionnaire, 1 represents the slightest symptoms and best function and 5 represents the most severe symptoms and the worst function. The average score is calculated by dividing the whole score by the number of questions. Also we used a grading score based on patients' clinical symptoms ranging from 1 to 5.1 indicates the weakest symptoms and 5 shows the most severe symptoms.

\subsection{Statistical analysis}

Statistical analyses were performed using the Statistical Package of Social Science software (SPSS version 16; SPSS, Inc., Chicago, IL, USA). The difference between preoperative and postoperative BCTQ scores and CTS grades in each group was evaluated using the paired t-test. Comparison of pre and postoperative BCTQ scores between the two groups were performed using the independent $t$-test. Statistical significance was set at $\mathrm{P}<0.05$.

\subsection{Ethics}

The Ethic Committee of Shiraz University of Medical Sciences approved our study protocol. Patients were asked about their willingness to participate in a research study. Those patients who refused were assigned to receive standard treatment. Those patients who agreed to participate were informed about their operation and study process. Written consent was signed by them. 


\section{Results}

\subsection{Baseline characteristics}

A total of 47 patients ( 25 hypothyroid and 22 with normal thyroid function) with an average age of 44 were included in this study. No patient was left handed. 15 patients were male and 27 were female.

\subsection{Surgery outcomes}

The study showed that the grade of CTS decreased significantly 3 weeks after operation in comparison with preoperative grades $(p<0.001)$. A significant decrease was observed in the postoperative BCTQ scores of all patients, compared to preoperative ones $(p<0.001)$. This study also showed a decrease in BCTQ score in the three weeks postoperative follow up in comparison to postoperative BCTQ scores $(p<0.001)$ and preoperative ones $(\mathrm{p}<0.001)$. We demonstrated that the postoperative BCTQ scores of euthyroid patients decreased more in comparison with hypothyroid patents (Table 1). Also, BCTQ scores of euthyroid patients decreased more in three weeks after operation in comparison with hypothyroid patients (Table 1). The most significant BCTQ score decrease, which was 2.2 , was seen in two cases of euthyroid patients.

Table 1. Mean of postoperative and 3 weeks postoperative BCTQ score decrease in two groups

\begin{tabular}{|l|l|l|l|l|l|}
\hline Patients & Count & $\begin{array}{l}\text { Mean of BCTQ score decrease } \\
\text { postoperative }\end{array}$ & $\begin{array}{l}\text { P } \\
\text { value }\end{array}$ & $\begin{array}{l}\text { Mean of BCTQ score decrease 3 } \\
\text { week postoperative }\end{array}$ & $\begin{array}{l}\text { p- } \\
\text { value }\end{array}$ \\
\hline Hypothyroid & 25 & 0.148 & $<0.001$ & 0.168 & $<0.001$ \\
\hline Euthyroid & 22 & 1.131 & $<0.001$ & 1.83 & $<0.001$ \\
\hline
\end{tabular}

\section{Discussion}

In present study, we have compared the BCTQ scores in patients with and without hypothyroidism who underwent carpal tunnel release. CTS is known as one of the most common complaints of hand and wrist $(9,10)$. The compression of the median nerve under a ligament at the wrist level causes numbness and tingling radiating to fingers (10). These symptoms may also be accompanied by pain and loss of strength (4).Although electrophysiological studies reported to be normal in $22 \%$ of the patients who were definitely diagnosed with CTS by means of clinical signs and symptoms, it is still used as one of the primary investigations (11). In this study, electrophysiological findings were complete along with clinical symptoms. Sensorial nerves, primarily the sural nerves, show the first signs of conduction of abnormality among patients with newly diagnosed hypothyroidism (12, 13). Based on the electrophysiological study findings, Yuksel et al. showed that the median motor and sensory nerves were affected the most compared to other nerves (14). Using the same diagnostic setting Somay et al., found that sensory nerves were mostly affected among hypothyroid patients (15). In a paired comparison study, published by Oktayoglu et al., it was revealed that right and left median sensory nerve conduction velocity decreased, distal latency increased and SNAP values decreased significantly in the hypothyroid group compared to the control group (6). They proposed that electrophysiological studies are of great value to detected entrapment neuropathies at an early stage even if the patient does not indicate any neurological or clinical symptoms $(6,16)$. These studies had an influence on better understanding of CTS in hypothyroidism but the fact that they lacked participants makes their conclusions indefinite.

In order to overcome the effect of small sample sizes on the association of CTS and hypothyroidism, Shiri et al. ran a meta-analysis study. Eighteen studies were selected. They found if studies which did not control any confounder were included, an association between a thyroid disease, whether hypo- or hyperthyroidism and CTS, is seen (N59,573, effect size [ES]51.32 (95\% CI: 1.04-1.68) as well as between hypothyroidism and CTS (N564,531, ES52.15 [95\% CI, 1.64-2.83]). But when the study is limited to the previous papers which controlled some potential confounders such as rheumatoid arthritis and overweight, the association between a thyroid disease and CTS disappeared(N54,799, ES51.17 [95\% CI,0.71-1.92], I250\%). The author came to this conclusion that only a modest association between hypothyroidism and CTS is present (17). In this study, we were unable to define the association between hypothyroidism and CTS because of selection bias. Splinting, therapy, and locally injected drugs have been considered as different conservative management of CTS (18). Randomized clinical studies investigating the effect of non-surgical treatment for CTS have been reviewed by Gerritsen et al, and it was reported that these treatments had little impact on long term symptom-free periods in CTS patients (19). On the other hand, the studies that have revealed the effect of nonsurgical treatment also have claimed recurrence of positive results with the passage of time $(20,21)$ which would cause additional treatment in the future leading to an increase in costs. We showed that early post-operative results of carpal tunnel release would be promising for both hypothyroid and euthyroid patients. In a randomized controlled trial by Jarvik et al., 116 patients were randomly assigned to surgery or a conservative 
treatment group. They reported that in patients with carpal tunnel syndrome without denervation, surgery had slightly improved hand function and symptoms within 3 months, compared with a conservative treatment. Although some patients who underwent surgery reported persistent symptoms these advantageous results claimed to persist for 1 year (8). Hypothyroid patients may have shown less success in conservative treatment which would lead to surgery (17). In this study we are not able to make any comments on this topic, as we had assigned our hypothyroid patients straight to surgery without prior conservative surgery. But the fact that euthyroid patients had lower scores in the BCTQ on post-operative day and on three weeks after surgery, indicates that surgery may have better results in patients with normal levels of thyroid hormones. We reported lower scores of BCTQ in patients with hypothyroidism. Considering the items in this questionnaire, it means these patients had worse symptoms compared to euthyroid patients. This finding may raise the notion that if hypothyroidism is treated, patients would have less symptoms, but it has been shown that CTS symptoms are also seen, even when hypothyroid patients have euthyroid (22) or when they were on levothyroxine therapy $(3,23)$.

\section{Conclusions}

In this study we found that hypothyroid patients had lower post-operative BCTQ score which indicate that hypothyroidism affects CTS symptoms severity and postoperative results of carpal tunnel release. Considering the difference between post-operative results of hypothyroid and euthyroid patients, hypothyroidism should be treated prior to surgical intervention in order to have more favorable results. Future studies should be dedicated to investigate the impact of time intervals between hypothyroidism treatment and carpal tunnel release surgery.

\section{Acknowledgments:}

The present article was extracted from the thesis written by Sahameddin Mortazavi for his post-graduation thesis and was financially supported by Shiraz University of Medical Sciences (grant number: 87/1003). Authors would like to thank all the staff of Shahid Faghihi hospital for their kind coopration running this study.

\section{Conflict of Interest:}

There is no conflict of interest to be declared.

\section{Authors' contributions:}

All authors contributed to this project and article equally. All authors read and approved the final manuscript.

\section{References:}

1) Pyun SB, Song W, Yoo SD. Slowed conduction velocity of the median sensory nerve across the carpal tunnel in normal adults. Am J Phys Med Rehabil. 2005; 84(8): 598-603. doi: 10.1097/01.phm.0000171004.38035.9e. PMID: 16034229.

2) Viera AJ. Management of carpal tunnel syndrome. Am Fam Physician. 2003; 68(2): 265-72. PMID: 12892346.

3) Stevens JC, Beard CM, O'Fallon WM, Kurland LT. Conditions associated with carpal tunnel syndrome. Mayo Clin Proc. 1992; 67(6): 541-8. PMID: 1434881.

4) Tunc T, Kutlu G, Coskun O, Okuyucu EE, Çavdar L, İnan LE, et al. Karpal tunel sendromunda klinik ve elektrofizyolojik evrelemelerin karsilastirilmasi. 2006; 7: 23-6.

5) You H, Simmons Z, Freivalds A, Kothari MJ, Naidu SH. Relationships between clinical symptom severity scales and nerve conduction measures in carpal tunnel syndrome. Muscle Nerve. 1999; 22(4): 497-501. doi: 10.1002/(SICI)1097-4598(199904)22:4<497::AID-MUS11>3.0.CO;2-T. PMID: 10204785.

6) Oktayoglu P, Nas K, Kilinç F, Tasdemir N, Bozkurt M, Yildiz I. Assessment of the Presence of Carpal Tunnel Syndrome in Patients with Diabetes Mellitus, Hypothyroidism and Acromegaly. J Clin Diagn Res. 2015; 9(6): 14-8. doi: 10.7860/jcdr/2015/13149.6101. PMID: 26266148 , PMCID: PMC4525537.

7) Duyff RF, Van den Bosch J, Laman DM, van Loon BJ, Linssen WH. Neuromuscular findings in thyroid dysfunction: a prospective clinical and electrodiagnostic study. J Neurol Neurosurg Psychiatry. 2000; 68(6): 750-5. doi: 10.1136/jnnp.68.6.750. PMID: 10811699, PMCID: PMC1736982.

8) Jarvik JG, Comstock BA, Kliot M, Turner JA, Chan L, Heagerty PJ, et al. Surgery versus non-surgical therapy for carpal tunnel syndrome: a randomised parallel-group trial. The Lancet. 2009; 374(9695): 107481. doi: 10.1016/S0140-6736(09)61517-8. PMID: 19782873.

9) Atroshi I, Gummesson C, Johnsson R, Ornstein E, Ranstam J, Rosén I. Prevalence of carpal tunnel syndrome in a general population. Jama1. 1999; 282(2): 153-8. doi: 10.1001/jama.282.2.153. PMID: 10411196 . 
10) Daniell WE, Fulton - Kehoe D, Franklin GM. Work - related carpal tunnel syndrome in Washington State workers' compensation: Utilization of surgery and the duration of lost work. Am J Ind Med. 2009; 52(12): 931-42. doi: 10.1002/ajim.20765. PMID: 19882743.

11) Witt JC, Hentz JG, Stevens JC. Carpal tunnel syndrome with normal nerve conduction studies. Muscle Nerve. 2004; 29(4): 515-22. doi: 10.1002/mus.20019. PMID: 15052616.

12) Beghi E, Delodovici M, Bogliun G, Crespi V, Paleari F, Gamba P, et al. Hypothyroidism and polyneuropathy. J Neurol Neurosurg Psychiatry. 1989; 52(12): 1420-3. doi: 10.1136/jnnp.52.12.1420. PMID: 2559162, PMCID: PMC1031603.

13) Arikanoglu A, Altun Y, Uzar E, Acar A, Çevik MU, Demircan F, et al. Klinik ve Subklinik Hipotiroidili Hastalarda Median ve Ulnar Sinirin Elektrofizyolojik İncelemeleri: Olgu Kontrol Çalışması. Archives of Neuropsychiatry/Noropsikiatri Arsivi. 2012; 49(4): 304-7.

14) Gulbun Y, Karlikaya G, Tulin T, Gulseren A. Nerve Conduction Studies, SEP and Blink Reflex Studies in Recently Diagnosed, Untreated Thyroid Disease Patients. Journal of Neurological Sciences (Turkish). 2006; 24(1): 007-15.

15) Somay G, Oflazoğlu B, Us O, Surardamar A. Neuromuscular status of thyroid diseases: a prospective clinical and electrodiagnostic study. Electromyogr Clin Neurophysiol. 2006; 47(2): 67-78. PMID: 17479722 .

16) Kececi H, Degirmenci Y. Hormone replacement therapy in hypothyroidism and nerve conduction study. Neurophysiol Clin. 2006; 36(2): 79-83. doi: 10.1016/j.neucli.2006.04.001. PMID: 16844546.

17) Shiri R. Hypothyroidism and carpal tunnel syndrome: A meta - analysis. Muscle \& nerve. 2014; 50(6): 879-83. doi: 10.1002/mus.24453. PMID: 25204641.

18) Pomerance J, Zurakowski D, Fine I. The cost-effectiveness of nonsurgical versus surgical treatment for carpal tunnel syndrome. J Hand Surg Am. 2009; 34(7): 1193-200. doi: 10.1016/j.jhsa.2009.04.034. PMID: 19700068.

19) Gerritsen AA, de Krom MC, Struijs MA, Scholten RJ, de Vet HC, Bouter LM. Conservative treatment options for carpal tunnel syndrome: a systematic review of randomised controlled trials. J Neurol. 2002; 249(3): 272-80. doi: 10.1007/s004150200004. PMID: 11993525.

20) Marshall S, Tardif G, Ashworth N. Local corticosteroid injection for carpal tunnel syndrome. Cochrane Database Syst Rev. 2007; (2): 1554. doi: 10.1002/14651858.cd001554.pub2. PMID: 17443508.

21) O'Connor D, Marshall S, Massy-Westropp N. Non - surgical treatment (other than steroid injection) for carpal tunnel syndrome. Cochrane Database Syst Rev. 2003; (1): 3219. doi: 10.1002/14651858.cd003219. PMID: 12535461.

22) Palumbo CF, Szabo RM, Olmsted SL. The effects of hypothyroidism and thyroid replacement on the development of carpal tunnel syndrome. J Hand Surg Am. 2000; 25(4): 734-9. doi: 10.1053/jhsu.2000.8642. PMID: 10913216.

23) Karpitskaya Y, Novak CB, Mackinnon SE. Prevalence of smoking, obesity, diabetes mellitus, and thyroid disease in patients with carpal tunnel syndrome. Ann Plast Surg. 2002; 48(3): 269-73. doi: 10.1097/00000637-200203000-00007. PMID: 11862031. 